\title{
Double VEGF/HGF Gene Therapy in Critical Limb Ischemia Complicated by Diabetes Mellitus
}

\author{
Piotr Barć $^{1}$ (D) Maciej Antkiewicz ${ }^{1} \cdot$ Barbara Śliwa $^{1} \cdot$ Katarzyna Frączkowska $^{1}$ (D) Maciej Guziński $^{2}$. \\ Tomasz Dawiskiba $^{1}$ - Małgorzata Małodobra-Mazur ${ }^{3}$ - Wojciech Witkiewicz ${ }^{4}$ Diana Kupczyńska ${ }^{1}$. \\ Bartlomiej Strzelec $^{1} \cdot$ Dariusz Janczak $^{1}$ - Jan Pawel Skóra ${ }^{1}$
}

Received: 3 April 2020 / Accepted: 2 August 2020 / Published online: 1 September 2020

(C) The Author(s) 2020

\begin{abstract}
Critical leg ischemia (CLI) complicated by diabetes mellitus (DM), which is a very common and dangerous disease, represents the ultimate stage of peripheral arterial disease. Patients are treated with antiplatelet drugs, statins and limb revascularization, but a significant number of patients are not candidate for revascularization. Literature shows that in such cases, gene therapy could be a perfect therapeutic option. The aim of our study was to evaluate efficacy of double vascular endothelial growth factor/ hepatocyte growth factor (VEGF/HGF) gene therapy in patients with CLI complicated by DM. We observed that 90 days after administration, serum level of VEGF and ankle-brachial index increased significantly $(p<0.001)$ and rest pain decreased significantly compared with the control group $(p<0.002)$. Moreover considerable improvement in vascularization was observed in computed tomography angiography $(P=0.04)$. Based on the results of this study, we suggest that the therapy with pIRES/ VEGF165/HGF bicistronic plasmid administration is a safe and effective method of treatment of patients with both CLI and DM.
\end{abstract}

Keywords Gene therapy · VEGF · HGF · Critical limb ischemia $\cdot$ Diabetes mellitus $\begin{array}{ll}\text { VAS } & \text { Visual analogue scale } \\ \text { VEGF } & \text { Vascular endothelial growth factor }\end{array}$

\section{Introduction}

Critical leg ischemia (CLI) indicates the final stage of peripheral arterial disease (PAD). Due to the fact that CLI is most commonly caused by atherosclerosis obliterans, it is heavily associated with smoking and diabetes mellitus (DM) $[5,6$, 17]. PAD leads to approximately 500-1000 new cases of CLI per million people per year and it touches men three times more often than women [1-3, 5, 6, 17]. Revascularization is a cornerstone of therapy to prevent limb amputation, and despite advance in both open and endovascular surgery, many

Associate Editor Junjie Xiao oversaw the review of this article

Maciej Antkiewicz

maciej.antkiewicz@gmail.com

1 Department and Clinic of Vascular, General and Transplantation Surgery, Jan Mikulicz-Radecki Medical University Hospital, Wroclaw Medical University, Wroclaw, Poland
2 Department of Radiology, Jan Mikulicz-Radecki Medical University Hospital, Wroclaw Medical University, Wroclaw, Poland

3 Molecular Techniques Unit, Wroclaw Medical University, Wroclaw, Poland

4 Regional Specialized Hospital in Wroclaw, Research and Development Center, Wroclaw, Poland 
patients are doomed to leg dismemberment. The facts that about one-third of people suffering from CLI in United States are poor or no-option patients and that $30 \%$ of CLI patients have to undergo leg amputation with mortality rate of $20 \%$ or higher show that this disease makes serious problem nowadays [3-7, 13, 17]. Because there is no directly CLI aimed medication, the only cure for "not candidate for revascularisation" (NCR) patients is oral antiplatelet drugs, statins, treatment of DM and smoking cessation. Nevertheless, this patients' cohort has a particularly poor prognosis, including a 1 year amputation rate of $40 \%$ and a mortality as high as $20 \%$ [4-6]. Salvation is offered by therapeutic angiogenesis, which by administration of angiogenic molecules directly to damaged tissues leads to formation of new vessels. Angiogenic gene therapy trials were seen a few years ago as a promising emerging therapy for different types of ischemia. We found many studies testing gene therapy in treatment of various diseases caused by ischemia with miscellaneous outcomes $[8,9,12-14,16,21,28]$. Many of angiogenic factors such as vascular endothelial growth factor (VEGF), fibroblast growth factors (FGF1 and FGF2), or hepatocyte growth factor (HGF) were tested in clinical trials. HGF provides the best results but is still not sufficient alone $[2,9,20,25]$. Also, VEGF encoding plasmid seemed to be inefficient in single therapy $[9,12,14,16,27]$. The poor outcome of therapy aimed on administration of only one angiogenic factor is probably caused by the fact that the angiogenic process requires coordinated expression of multiple genes $[9,10,12,14,20]$. However, VEGF is the key factor in angiogenesis by stimulating the proliferation and migration of endothelial cells, which leads to the formation of new vessels. This process also requires the presence of other growth factors such as HGF $[2,10,20,25,27]$. The HGF receptor is present on various types of cells including endothelium $[2$, 20]. Some studies report that presence of HGF in extracellular matrix multiplies the activity of VEGF during angiogenesis $[2,20,25]$. Unfortunately, protein forms of angiogenic factor have many limitations, such as low protein stability, rapid rate of cellular internalization, and relatively short half-life (for VEGF is 40 min under cellular conditions in vitro) [19, 24]. A way to bypass these obstacles is to use plasmid coding cytokines.

Based on previous studies and the fact that angiogenesis is a complicated process that requires many proangiogenic factors for proper vessel formation, we have developed bicistronic vectors carrying plasmid of the internal ribosome entry site pIRES/VEGF165/HGF encoding human VEGF165 and HGF, which is a novel therapy of CLI and DM based on dual gen construction. The aim of the present study was to assess the safety, feasibility, and clinical efficacy of intramuscular application of this bicistronic plasmid vectors in patients with CLI and DM. In addition, results of present study will be used to estimate the development of angiogenesis caused by expression of two angiogenic cytokines VEGF and HGF.

\section{Methods}

\section{Plasmid DNA Preparation}

Bicistronic plasmid has been designed based on our previous research. We have used CMV promoter because it showed significant transfection efficiency in vitro [22]. We present the schematic diagram of the plasmid structure (Fig. Fig. 1).

Human HFG and VEGF165 cDNA were prepared as described previously [2]. Both cDNAs were cloned into pIRES bicistronic plasmid with the restriction enzymes. All plasmids pIRES/VEGF165/HGF prepared in this way were purified, dissolved and their apyrogenicity was confirmed. The whole process was already described in detail [2].

\section{Patient Cohort}

The inclusion criteria for this study were (1) type $2 \mathrm{DM}$, (2) CLI, including rest pain and non-healing ischemic ulcers persisting for at least 12 weeks or gangrene, (3) resistance to conventional therapy of CLI for at least 4 weeks after hospitalization, (4) ankle-brachial index (ABI) of less than 0.4 in the affected limb and (5) NCR. Patients with the following conditions were excluded: severe retinopathy, end-stage renal disease, heart failure, angina pectoris, New York Heart Association (NYHA) Classification III or IV, liver dysfunction (grade $\mathrm{B}$ or $\mathrm{C}$ in the Child-Pugh classification), malignancy, history of malignancy, inability to stand or walk without

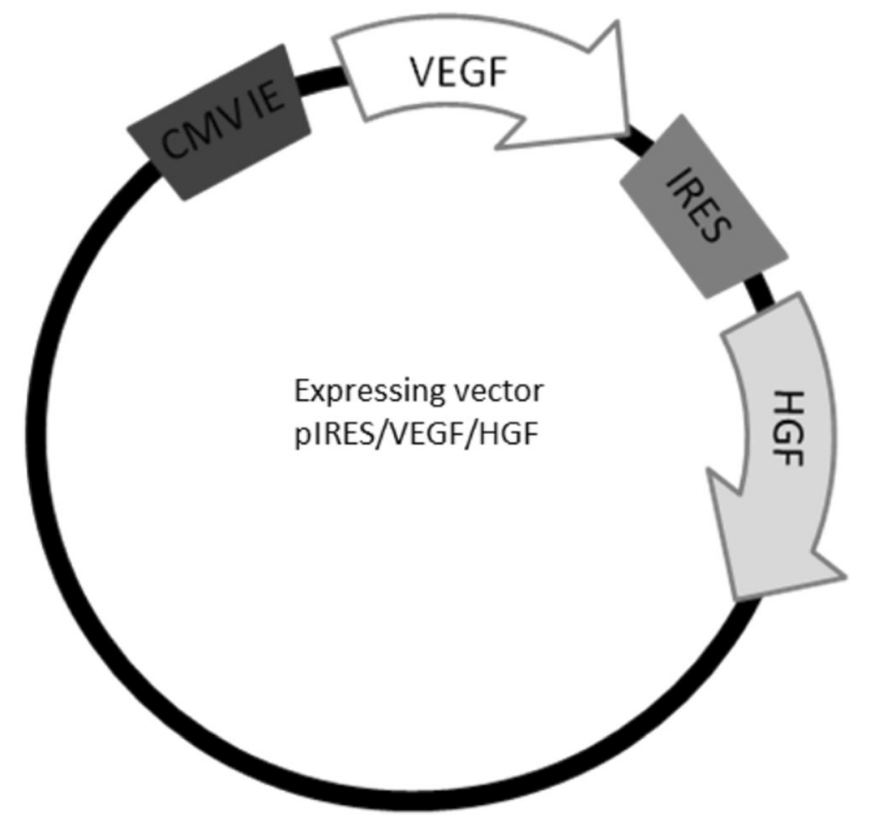

Fig. 1 Schematic diagram of the plasmid structure 
help. Twenty-eight patients were enrolled in the study. They were randomized into two equal groups. Fourteen patients (ten men and four women aged from 58 to 81 years - average age 65.8) underwent bicistronic pIRES/VEGF 165/HGF therapy-group 1 . The remaining patients (nine men and five women aged from 40 to 85 years - average age 68.3) as control group did not receive plasmids - group 2. The duration of DM for all the patients ranged from 6.5 to 28 years. They required constant insulin administration every day with an average dose of $0.73 \mathrm{U} / \mathrm{kg}$ (range from 0.48 to $0.91 \mathrm{U} / \mathrm{kg}$ per day). The average haemoglobin A1c level was 8,7.1\% (range from 6.3-12.1\%). All patients from both groups were followed for 4 weeks under conventional conditions (antiplatelet and statin drugs, maintain normal glucose levels, physical training, wound debridement and broad-spectrum antibiotics if ulcers showed clinical signs of infection).

\section{Administration of Bicistronic Plasmid}

Intramuscular injection of pIRES/VEGF165/HGF was performed into the ischemic lower limb above and below the knee level. Each patient received $4 \mathrm{mg}$ of bicistronic plasmid. The injection sites to muscles were based on our previous study and literature data $[15,21]$. The volume of each injection was $2.5 \mathrm{~mL}$ (approximately 80 injections, $2 \mathrm{~cm}$ deep into muscles of ischemic limb along each of the three crural arteries). The duration of injections did not exceed $1 \mathrm{~h}$.

\section{Clinical Assessment}

One, 4 and 12 weeks after treatment initiation, all patients were tested for haemoglobin, thrombocytes, leukocytes, Creactive protein, creatinine and haemoglobin A1c levels. Heart rate, blood pressure and body temperature were also measured.

\section{Level of VEGF in Serum}

Venous blood of patients in group 1 was taken from the upper limb to assess VEGF165 concentration. Test was performed before receiving plasmid injection, 7, 14, 28 and 90 days after. Serum was centrifuged, frozen, then evaluated using ELISA method.

\section{$\mathbf{A B I}$}

ABI was recorded 1 week before, 1 and 3 months after the treatment initiation in both groups of patients. It was calculated as the ratio of the lowest pressure from either the anterior or posterior tibial artery divided by the greatest brachial systolic pressure.

\section{Rest Pain}

Rest pain was examined 1 week before, 1 and 3 months after the treatment initiation in both groups of patients. Pain assessment was evaluated using a self-administered visual analogue scale (VAS, 0-10).

\section{Computed Tomography Angiography}

Computed tomography angiography (CTA) performed using a GE Medical Systems LightSpeed 16-slice device was used to evaluate the arterial supply of the lower limb in all patients. The first examination was carried out 1 week before the treatment initiation. The follow-up examination was performed 3 months after the initial test. CTA was performed after intravenous administration of $150 \mathrm{~mL}$ (ca $2 \mathrm{~mL} / \mathrm{kg}$ b.w.) non-ionic agent.

\section{Statistical Analysis}

Statistica 13.3 (StatSoft Polska) was used for statistical analysis. The following tests were used in the study: paired Chi-squared, Wilcoxon and Student's $t$ tests. Continuous variables were compared before and after therapy analysed by groups and time points. $P<0.05$ was considered significant.

\section{Results}

\section{Clinical Follow-Up}

Intramuscular injections of bicistronic plasmid were administrated to 14 patients of group 1 . The therapy was well tolerated and there were no major complications. Several minor complications occurred within $24 \mathrm{~h}$ following injections: tenderness at the injection sites (two patients) and fever (three patients). During our study, all the patients from both groups had no significant changes in laboratory parameters; none of them was hospitalized during follow-up. Some of the patients obtained surgical debridement of necrotic tissue. Two patients on group 1 and four patients in group 2 required limb amputation because of advanced CLI (necrosis, wide ulcerations and severe infection).

All six patients were amputated below the knee. Comparing both groups, the wounds healed significantly better in group 1 (all patients while excluding amputated ones) than in group 2 (there were no complete healing). We present pictures of limb before and 3 months after bicistronic plasmid injections (Fig. 2). 
Fig. 2 Clinical presentation; a: before plasmid administration; $b$ : after 3 months from plasmid administration

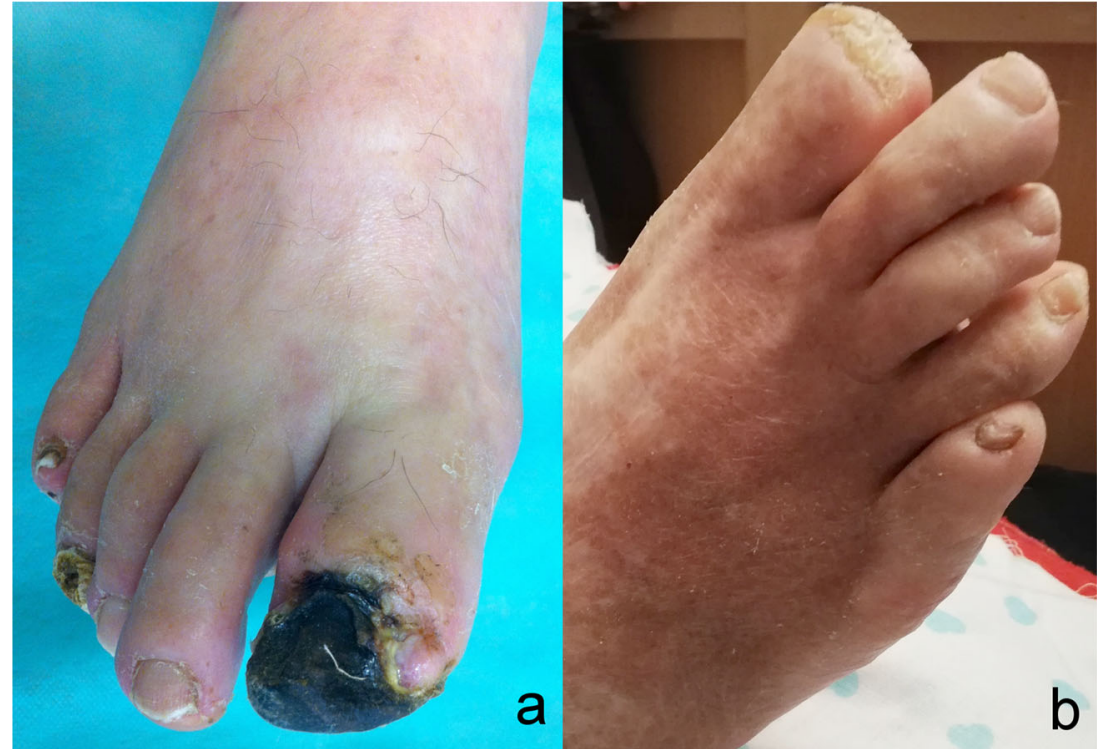

\section{Level of VEGF in Serum}

During our 90-day observation period, level of VEGF was measured in group 1, showing that fluctuations in cytokine VEGF levels occurred. Mean VEGF serum levels, as presented in Table 1, increased significantly from $235 \pm 83$ to $398 \pm 78 \mathrm{pg} / \mathrm{L}(p<0.001) 1$ month after gene therapy. It was the highest mean serum level recorded during this study. However, the changes of VEGF levels were highly variable.

\section{Rest Pain (VAS)}

We measured pain in all the patients (both groups) by VAS. There was significant decrease of pain in group 1: from $6.7 \pm$ 1.4 to $1.3 \pm 1.13$ months after plasmid injections $(p<0.002)$. The best results concerned 12 patients from group 1, who obtained complete ulcer healing, while pain outcome in group 2 did not decrease significantly.

\section{Plasma Glucose Levels}

Fasting plasma glucose level was adequate to guidelines of Polish Diabetes Association throughout observation and ranged between 6.5 and $8 \mathrm{mmol} / \mathrm{L}$.

\section{ABI Results}

The mean ABI increased significantly in group 1 from $0.28 \pm$ 0.22 to $0.51 \pm 0.29(p<0.001) 4$ weeks after the administration of bicistronic plasmid. At the end of the study (after 3 months), the index increased significantly to $0.49 \pm 0.30$ (Table 2). In group 2, ABI results were as follows: $0.31 \pm$ 0.27 before treatment, $0.36 \pm 0.32$ after 1 month, $0.32 \pm 0.28$ after 3 months. Results between groups changed significantly $(P=0.03)$. Six patients (two in group 1 , four in group 2$)$ did not have a chance to complete the $\mathrm{ABI}$ examination due to amputation.

\section{CTA}

We performed CTA before and 90 days after plasmid administration. The radiologist, who evaluated CTA, did not know the patients and their treatment status. CTA documented typical findings of progressive peripheral atherosclerotic changes typical for diabetic microangiopathy in all 28 cases. These findings included segmental occlusive disease involving primarily the distal superficial femoral artery and/or the popliteal artery. We compared the results by calculating visible collateral vessels (Table 3). Three months after administration of bicistronic plasmid, formation of new collateral vessels was observed in all group 1 patients without amputation: from

Table 1 Plasma level of VEGF (mean $\pm \mathrm{SD} ; P<0.001$ )

\begin{tabular}{llllll}
\hline $\begin{array}{l}\text { Time of } \\
\text { measurement }\end{array}$ & $\begin{array}{l}\text { Before } \\
\text { administration }\end{array}$ & $\begin{array}{l}7 \text { days after } \\
\text { administration }\end{array}$ & $\begin{array}{l}\text { 14 days after } \\
\text { administration }\end{array}$ & $\begin{array}{l}28 \text { days after } \\
\text { administration }\end{array}$ & $\begin{array}{l}90 \text { days after } \\
\text { administration }\end{array}$ \\
\hline Level of VEGF & $235 \pm 83$ & $342 \pm 85$ & $391 \pm 82$ & $398 \pm 78$ & $395 \pm 69$ \\
\hline
\end{tabular}


Table 2 ABI results (mean $\pm \mathrm{SD} ; P=0.03$ )

\begin{tabular}{llll}
\hline Time of measurement & One week before & One month after & Three months after \\
\hline Group 1 (received plasmid) & $0.28 \pm 0.22$ & $0.47 \pm 0.29$ & $0.51 \pm 0.30$ \\
Group 2 (control group) & $0.31 \pm 0.27$ & $0.36 \pm 0.32$ & $0.32 \pm 0.28$ \\
\hline
\end{tabular}

$106.7 \pm 24.5$ to $127.6 \pm 27.6$. It is statistically significant $(P=$ 0.04 ) improvement compared with the group 1. Angiograms (Fig.s 3 and 4) showed qualitative evidence of improved distal flow after the gene.

\section{Discussion}

CLI is a life-limiting and life-threatening condition, which is mainly treated by risk factor modification and revascularization [15]. However, a large number of patients are NCR. In these cases, when pharmacological treatment is ineffective or insufficient, double VEGF/HGF gene therapy might be an attractive option. It is well known that VEGF, HGF, or FGF are key factors in the process of proliferation and revascularization [11]. We know that these molecules are produced in case of ischemia and their level depends on intensity of the process [26]. Our therapy leads to an increase in the level of proangiogenic factors in affected tissues. As alluded previously, there are studies showing that the release of HGF to extracellular matrix increases the activity of VEGF during neoangiogenesis $[2,20,25]$. Based on the evidence outlined above, we believe that double gene therapy has the potential to be more efficient than the single gene therapy.

This study examined the safety and efficacy of bicistronic gene therapy in patients suffering from CLI complicated by DM. There is a number of reports of using HGF plasmid, FGF or VEGF alone or combined with stem cells in treatment of CLI with good or moderate effect [18, 23]. There were attempts of using gene therapy based on intramuscular injections of VEGF or FGF plasmids in coronary heart disease with rather poor outcomes. To our knowledge, however, this is the first study describing the application of pIRES/VEGF165/ HGF therapy using bicistronic plasmid administration in patients with CLI and DM. The treatment regimen described in this study displayed high efficacy with little side effects which is in line with previously published studies of similar therapeutic interventions. The ABI improved and rest pain

Table 3 CTA results - number of visible collateral vessels (mean $\pm \mathrm{SD}$; $P=0.04)$

\begin{tabular}{lll}
\hline Time of measurement & Before treatment & Three months after \\
\hline Group 1 (received plasmid) & $106.7 \pm 24.5$ & $127.6 \pm 27.6$ \\
Group 2 (control group) & $106.3 \pm 22.6$ & $112.6 \pm 20.9$ \\
\hline
\end{tabular}

decreased significantly after 3 months. The CTA demonstrated considerable improvement of vascularization. Additionally, no serious complications were observed. Despite the positive findings of this study, we suggest that further studies should focus on maximizing the efficacy of double gene therapy by improving technical aspects of the procedure. Preprocedural mapping of areas with vascular deprivation with adequate imaging and image guidance for gene delivery directly to the muscular site of interest, which is missing in many of the gene transfer studies, would certainly limit the unintended delivery of therapeutic agents to the fascia or subcutaneous tissue [15]. To address this issue, in order to maximize the efficacy of our treatment, we were giving intramuscular injections near the major affected artery. We evaluated the arteries before therapy using CTA and in physical examination based on common knowledge from

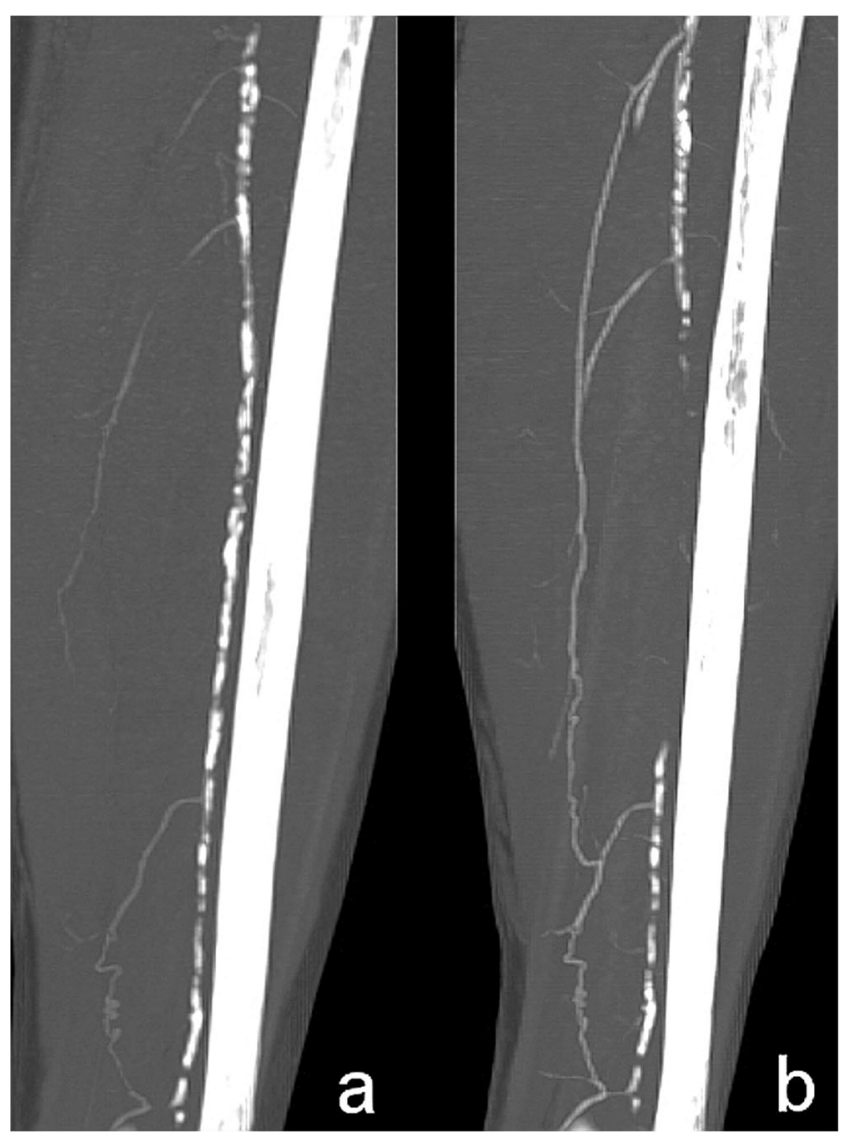

Fig. 3 CTA angiograms - femoral longitudinal projection, shows the increase in length of collaterals; $a$ : before plasmid administration; $b$ : after 3 months from plasmid administration 


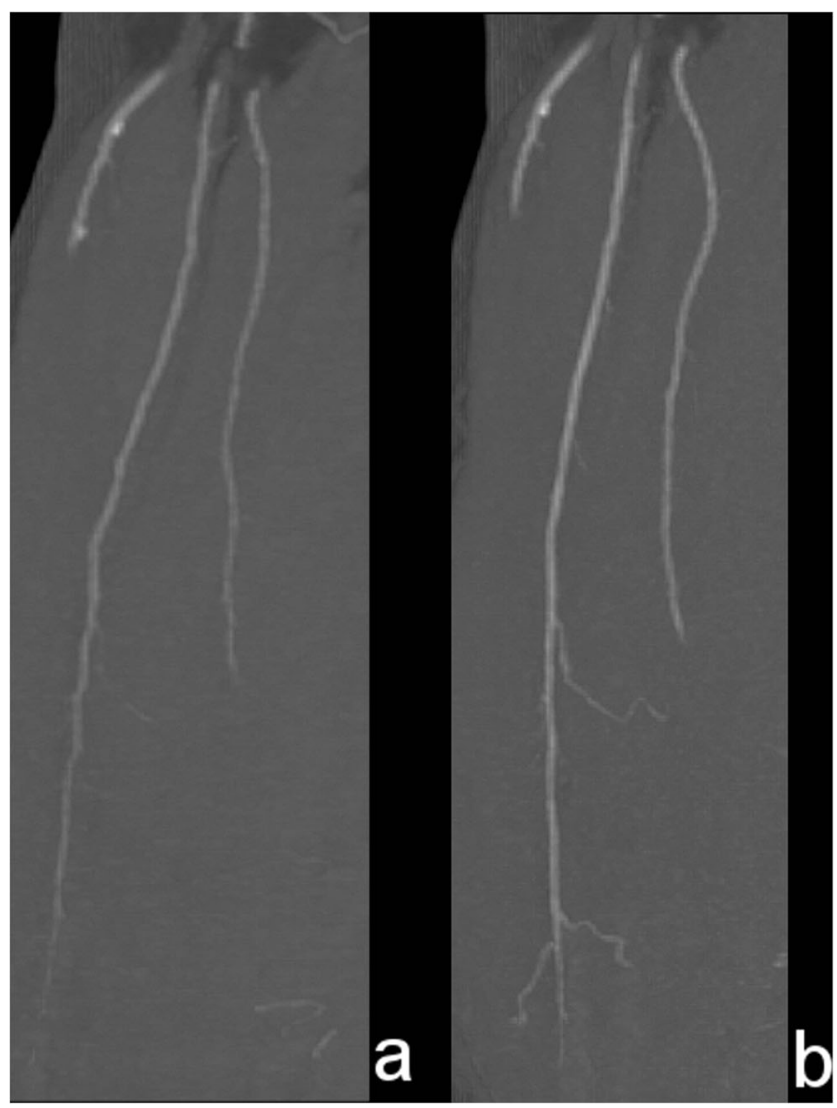

Fig. 4 CTA angiograms - lower leg longitudinal projection, shows the increase in length of collaterals; $a$ : before plasmid administration; $b$ : after 3 months from plasmid administration

angiostomy. In fact, the injection technique utilized in this study was similar to that previously used by Amman et al. with intramuscular injection of bone marrow mononuclear cells in patients with CLI [1].

The study described above, despite showing positive results, also has a number of limitations. The control group was not placebo-controlled or double blind. ABI which we used to assess the efficacy of the therapy might not be a sensitive test in DM patients. The VAS scale used in this study can also be subjective. Due to financial restrictions, we were not able to verify pIRES/VEGF165/HGF in human cell lines in vitro. For the same reason, we could measure only VEGF plasma level in therapeutic group, not both: VEGF and HGF in both groups.

Despite these limitations, the treatment regimen described in this study led to a highly statistically significant improvement in outcomes in patients and has considerably improved their quality of life. Based on the results of this study, we suggest that the pIRES/VEGF165/HGF therapy using bicistronic plasmid administration is a safe and effective method of treating patients with both CLI and DM. The fact that patients suffering from both CLI and DM often present with additional comorbidities and are likely to undergo procedures such as leg amputations makes the findings of our study all the more important. It should be noted that the effectiveness of this treatment is highly dependent on its early application in the disease progression. Further clinical studies with larger sample sizes should be performed to confirm the efficacy and safety of the pIRES/VEGF165/HGF therapy in CLI and DM.

Funding Information This publication is a part of Project "WroVasc Integrated Cardiovascular Centre", co-financed by the European Regional Development Fund, within Innovative Economy Operational Program, 2007-2013 realized in Regional Specialist Hospital, Research and Development Center in Wroclaw. "European Funds - for the development of innovative economy". Project supported by Wroclaw Centre of Biotechnology, programme The Leading National Research Centre (KNOW) for years 2014-2018.

\section{Compliance with Ethical Standards}

Conflict of Interest The authors declare that they have no conflict of interest.

Human Subjects/Informed Consent Statement All procedures followed were in accordance with the ethical standards of the responsible committee on human experimentation (institutional and national) and with the Helsinki Declaration of 1975 , as revised in 2000. The protocol of this study was approved by the Commission of Bioethics at the Wroclaw Medical University (Approval no. KB926/2003). Informed consent was obtained from all patients for being included in the study.

Open Access This article is licensed under a Creative Commons Attribution 4.0 International License, which permits use, sharing, adaptation, distribution and reproduction in any medium or format, as long as you give appropriate credit to the original author(s) and the source, provide a link to the Creative Commons licence, and indicate if changes were made. The images or other third party material in this article are included in the article's Creative Commons licence, unless indicated otherwise in a credit line to the material. If material is not included in the article's Creative Commons licence and your intended use is not permitted by statutory regulation or exceeds the permitted use, you will need to obtain permission directly from the copyright holder. To view a copy of this licence, visit http://creativecommons.org/licenses/by/4.0/.

\section{References}

1. Amann, B., Luedemann, C., Ratei, R., \& Schmidt-Lucke, J. A. (2009). Autologous bone marrow cell transplantation increases leg perfusion and reduces amputations in patients with advanced critical limb ischemia due to peripheral artery disease. Cell Transplantation, 18(3), 371-380. https://doi.org/10.3727/ 096368909788534942.

2. Barć, P., Antkiewicz, M., Śliwa, B., Baczyńska, D., Witkiewicz, W., \& Skóra, J. P. (2019). Treatment of critical limb ischemia by pIRES/VEGF165/HGF administration. Annals of Vascular Surgery, 60, 346-354. https://doi.org/10.1016/j.avsg.2019.03.013.

3. Davies, M. G. (2012). Critical limb ischemia: cell and molecular therapies for limb salvage. Methodist DeBakey Cardiovascular Journal, 8(4), 20-27. https://doi.org/10.14797/mdcj-8-4-20.

4. Fabiani, I., Calogero, E., Pugliese, N. R., Di Stefano, R., Nicastro, I., Buttitta, F., et al. (2018). Critical limb ischemia: a practical up-to- 
date review. Angiology, 69(6), 465-474. https://doi.org/10.1177/ 0003319717739387.

5. Farber, A., \& Eberhardt, R. T. (2016). The current state of critical limb ischemia: a systematic review. JAMA Surgery, 151(11), 10701077. https://doi.org/10.1001/jamasurg.2016.2018.

6. Fard, B., Dijkstra, P. U., Voesten, H. G. J. M., \& Geertzen, J. H. B. (2020). Mortality, reamputation, and preoperative comorbidities in patients undergoing dysvascular lower limb amputation. Annals of Vascular Surgery, 64, 228-238. https://doi.org/10.1016/j.avsg. 2019.09.010.

7. Freisinger, E., Malyar, N. M., Reinecke, H., \& Lawall, H. (2017). Impact of diabetes on outcome in critical limb ischemia with tissue loss: a large-scaled routine data analysis. Cardiovascular Diabetology, 16(1), 41. https://doi.org/10.1186/s12933-017-05248.

8. Hartikainen, J., Hassinen, I., Hedman, A., Kivelä, A., Saraste, A., Knuuti, J., et al. (2017). Adenoviral intramyocardial VEGF$\mathrm{D} \Delta \mathrm{N} \Delta \mathrm{C}$ gene transfer increases myocardial perfusion reserve in refractory angina patients: a phase I/IIa study with 1 -year follow-up. European Heart Journal, 38(33), 2547-2555. https://doi.org/10. 1093/eurheartj/ehx352.

9. Hedman, M., Muona, K., Hedman, A., Kivelä, A., Syvänne, M., Eränen, J., et al. (2009). Eight-year safety follow-up of coronary artery disease patients after local intracoronary VEGF gene transfer. Gene Therapy, 16(5), 629-634. https://doi.org/10.1038/gt.2009.4.

10. Inampudi, C., Akintoye, E., Ando, T., \& Briasoulis, A. (2018). Angiogenesis in peripheral arterial disease. Current Opinion in Pharmacology, 39, 60-67. https://doi.org/10.1016/j.coph.2018. 02.011 .

11. Jazwa, A., Florczyk, U., Grochot-Przeczek, A., Krist, B., Loboda, A., Jozkowicz, A., et al. (2016). Limb ischemia and vessel regeneration: is there a role for VEGF? Vascular Pharmacology, 86, 1830. https://doi.org/10.1016/j.vph.2016.09.003.

12. Johnson, T., Zhao, L., Manuel, G., Taylor, H., \& Liu, D. (2019). Approaches to therapeutic angiogenesis for ischemic heart disease. Journal of Molecular Medicine (Berlin, Germany), 97(2), 141-151. https://doi.org/10.1007/s00109-018-1729-3.

13. Kaminsky, S. M., Rosengart, T. K., Rosenberg, J., Chiuchiolo, M. J., van de Graaf, B., Sondhi, D., et al. (2013). Gene therapy to stimulate angiogenesis to treat diffuse coronary artery disease. Human Gene Therapy, 24(11), 948-963. https://doi.org/10.1089/ hum.2013.2516.

14. Kastrup, J., Jørgensen, E., Rück, A., Tägil, K., Glogar, D., Ruzyllo, W., et al. (2005). Direct intramyocardial plasmid vascular endothelial growth factor-A165 gene therapy in patients with stable severe angina pectoris a randomized double-blind placebo-controlled study: The Euroinject One trial. Journal of the American College of Cardiology, 45(7), 982-988. https://doi.org/10.1016/j.jacc.2004. 12.068 .

15. Kitrou, P., Karnabatidis, D., Brountzos, E., Katsanos, K., Reppas, L., \& Spiliopoulos, S. (2017). Gene-based therapies in patients with critical limb ischemia. Expert Opinion on Biological Therapy, 17(4), 449-456. https://doi.org/10.1080/14712598.2017.1289170.

16. Kukuła, K., Chojnowska, L., Dąbrowski, M., Witkowski, A., Chmielak, Z., Skwarek, M., et al. (2011). Intramyocardial plasmid-encoding human vascular endothelial growth factor A165/basic fibroblast growth factor therapy using percutaneous transcatheter approach in patients with refractory coronary artery disease (VIF-CAD). American Heart Journal, 161(3), 581-589. https://doi.org/10.1016/j.ahj.2010.11.023.

17. Madonna, R., \& Rokosh, G. (2012). Insights into gene therapy for critical limb ischemia: the devil is in the details. Vascular
Pharmacology, 57(1), 10-14. https://doi.org/10.1016/j.vph.2012. 05.001 .

18. Makino, H., Aoki, M., Hashiya, N., Yamasaki, K., Azuma, J., Sawa, Y., et al. (2012). Long-term follow-up evaluation of results from clinical trial using hepatocyte growth factor gene to treat severe peripheral arterial disease. Arteriosclerosis, Thrombosis, and Vascular Biology, 32(10), 2503-2509. https://doi.org/10.1161/ ATVBAHA.111.244632.

19. Mitchell, A. C., Briquez, P. S., Hubbell, J. A., \& Cochran, J. R. (2016). Engineering growth factors for regenerative medicine applications. Acta Biomaterialia, 30, 1-12. https://doi.org/10.1016/j. actbio.2015.11.007.

20. Muona, K., Mäkinen, K., Hedman, M., Manninen, H., \& YläHerttuala, S. (2012). 10-year safety follow-up in patients with local VEGF gene transfer to ischemic lower limb. Gene Therapy, 19(4), 392-395. https://doi.org/10.1038/gt.2011.109.

21. Rosengart, T. K., Bishawi, M. M., Halbreiner, M. S., Fakhoury, M., Finnin, E., Hollmann, C., et al. (2013). Long-term follow-up assessment of a phase 1 trial of angiogenic gene therapy using direct intramyocardial administration of an adenoviral vector expressing the VEGF121 cDNA for the treatment of diffuse coronary artery disease. Human Gene Therapy, 24(2), 203-208. https://doi.org/10. 1089/hum.2012.137.

22. Sadakierska-Chudy, A., Baczyńska, D., Skóra, J. P., Gębarowska, E., Pupka, A., \& Dorobisz, T. (2008). Transfection efficiency and cytotoxicity of transfection reagents in human umbilical vein endothelial cells. Advances in Clinical and Experimental Medicine, 6, 625-634.

23. Shigematsu, H., Yasuda, K., Sasajima, T., Takano, T., Miyata, T., Ohta, T., et al. (2011). Transfection of human HGF plasmid DNA improves limb salvage in Buerger's disease patients with critical limb ischemia. International angiology : a journal of the International Union of Angiology, 30(2), 140-149.

24. Vempati, P., Popel, A. S., \& Mac Gabhann, F. (2014). Extracellular regulation of VEGF: Isoforms, proteolysis, and vascular patterning. Cytokine \& Growth Factor Reviews, 25(1), 1-19. https://doi.org/ 10.1016/j.cytogfr.2013.11.002.

25. Wang, L.-S., Wang, H., Zhang, Q.-L., Yang, Z.-J., Kong, F.-X., \& Wu, C.-T. (2018). Hepatocyte growth factor gene therapy for ischemic diseases. Human Gene Therapy, 29(4), 413-423. https://doi. org/10.1089/hum.2017.217.

26. Wieczór, R., Rość, D., Wieczór, A. M., \& Kulwas, A. (2019). VASCULAR-1 and VASCULAR-2 as a new potential angiogenesis and endothelial dysfunction markers in peripheral arterial disease. Clinical and Applied Thrombosis/Hemostasis: Official Journal of the International Academy of Clinical and Applied Thrombosis/Hemostasis, 25, 1076029619877440. https://doi.org/ $10.1177 / 1076029619877440$.

27. Ylä-Herttuala, S. (2019). Gene therapy of critical limb ischemia enters clinical use. Molecular therapy : the journal of the American Society of Gene Therapy, 27(12), 2053. https://doi.org/ 10.1016/j.ymthe.2019.11.001.

28. Ylä-Herttuala, S., Bridges, C., Katz, M. G., \& Korpisalo, P. (2017). Angiogenic gene therapy in cardiovascular diseases: dream or vision? European Heart Journal, 38(18), 1365-1371. https://doi.org/ 10.1093/eurheartj/ehw547.

Publisher's Note Springer Nature remains neutral with regard to jurisdictional claims in published maps and institutional affiliations. 